\title{
Disclosure of financial competing interests in randomised controlled trials: cross sectional review
}

\author{
Cary P Gross, Anu R Gupta, Harlan M Krumholz
}

Section of General Internal Medicine, Department of Medicine,Yale University School of Medicine, 333 Cedar Street, New Haven, CT 06520, USA

Cary P Gross assistant professor

Robert Wood Johnson Clinical Scholars Program, Yale University School of Medicine Anu R Gupta clinical scholar

Section of Cardiovascular Medicine, Department of Medicine, Yale University School of Medicine

Harlan M Krumholz associate professor of medicine

Correspondence to: C P Gross

cary.gross@yale.edu

BMJ 2003;326:526-7
Financial relationships among industry, investigators, and academic institutions are growing increasingly complex, raising concerns about sponsors' considerable and perhaps inappropriate involvement in the conduct and reporting of biomedical research. ${ }^{12}$ Medical journals use disclosure as a primary mechanism for managing these conflicts, and many have adopted the 1997 uniform requirements for manuscripts submitted to biomedical journals to guide this process. $^{3}$

According to the 1997 uniform requirements, authors are asked to "acknowledge in the manuscript all financial support for their work." ${ }^{\text {"3 }}$ For industry support for specific projects, authors are asked to describe the sponsor's role in the design, analysis, and reporting of the study data. ${ }^{3}$ If there has been no such involvement, the manuscript is expected to explicitly state this fact. ${ }^{3}$

Previous work has shown that many published papers do not contain statements of financial competing interests. ${ }^{4}$ However, little is known about journals' adherence to other parts of the disclosure guidelines or about the nature of the interests that are being disclosed. We performed a cross sectional explicit review of published randomised controlled trials in five high impact medical journals to assess adherence to all the 1997 disclosure requirements and to document the specific nature of the disclosed interests.

\section{Methods and results}

All randomised controlled trials published in each issue of the Annals of Internal Medicine, the BMJ, JAMA, the Lancet, and the New England Journal of Medicine from 1 April 1999 to 31 March 2000 were identified. We focused on randomised controlled trials as they often have great impact on clinical medicine. Trials were excluded if they were follow up analyses of a previously published study. An abstractor used an explicit abstraction to record source(s) of study support, author-sponsor relationships, and the role of study sponsor. Disclosed author-sponsor relationships were coded as follows: advisory board, consultant/ honoraria, educational activities/speakers bureau, employment, grants, patent/licences, and stock. Study authors who had an industry address were categorised as employees.

We identified 268 trials: $16(6 \%)$ in the Annals of Internal Medicine, $47(18 \%)$ in the BMJ, $46(17 \%)$ in JAMA, $93(35 \%)$ in the Lancet, and $66(25 \%)$ in the New England Journal of Medicine. Of these, 238 (89\%) disclosed the source of study support (table).

The nature of the relationship between the authors and the study sponsor was included in 69 of the 100 industry sponsored studies (table). In the manuscripts that provided this information, the most commonly cited relationships were: employment (30/69, 43\%); consultant/honorarium (22, 32\%); grants (18, 26\%);
Compliance with requirement for disclosure of financial competing interests in randomised trials published April 1999 to March 2000

\begin{tabular}{lc} 
Requirement & Disclosure \\
\hline Source of study support: & \\
\hline Overall & $238 / 268$ \\
\hline Industry sponsored & 100 \\
\hline Non-industry sponsored & 135 \\
\hline Not disclosed & 30 \\
\hline Author-sponsor relationship*: & $69 / 100$ \\
\hline Overall & $30 \dagger$ \\
\hline Employment & $22 \dagger$ \\
\hline Consultant/honorarium & $18 \dagger$ \\
\hline Grants & $7 \dagger$ \\
\hline Educational/speakers bureau & $7 \dagger$ \\
\hline Stock ownership & $5 \dagger$ \\
\hline Advisory board & $1 \dagger$ \\
\hline Patent/licences & $8 / 100$ \\
\hline Role of study sponsor &
\end{tabular}

*Disclosure of author-sponsor relationship and role of study sponsor applicable to only 100 studies with industry support.

tOut of the 69 studies that disclosed author-sponsor relationship. Total number of studies is greater than 69 because 24 studies had multiple relations.

and stock ownership and participation in a speaker's bureau (7, 10\% each). The 30 manuscripts that were coauthored by employees of the industry sponsor represented $30 \%$ of published industry-sponsored studies and $11 \%$ of all randomised controlled trials in our sample.

Only eight of the 100 industry sponsored studies reported the role of the study sponsor in the methods section, as recommended by the uniform requirements. Of these studies, two manuscripts explicitly stated that the sponsor had no role in the study and six described the sponsor's role. Further analysis of these six studies found that the degree of sponsor involvement was highly variable and was usually described with vague wording. For instance, the sponsor's role in data analysis was described in terms ranging from "preliminary evaluation" to "coordinating data collection and statistical analysis."

\section{Comment}

Although industry involvement in published randomised controlled trials was substantial, the true extent and nature of financial relationships between investigators and industry is difficult to assess because of variable adherence to the disclosure guidelines. Recently, editors of prominent medical journals have moved beyond disclosure as a mechanism for managing competing interests. Editors will ask authors to document that they had access to the data and were able to make publication decisions independently. ${ }^{5}$ Poor adherence to the existing uniform requirements raises the question of the degree to which journals adhere to these more stringent requirements. 
Contributors: CPG was principal investigator and is guarantor. He designed the study along with ARG and HMK. Study data were abstracted by CPG and ARG. All authors collaborated on interpretation of the data and writing the manuscript.

Funding: No external funding.

Competing interests: None declared.

Blumenthal D. Ethics issues in academic-industry relationships in the life sciences: the continuing debate. Acad Med 1996;71:1291-6.
2 Bodenheimer T. Uneasy alliance-clinical investigators and the pharmaceutical industry. N Engl J Med 2000;342:1621-6.

3 Uniform requirements for manuscripts submitted to biomedical journals: International Committee of Medical Journal Editors. Ann Intern Med 1997;126:36-47.

4 Hussain A, Smith R. Declaring financial competing interests: survey of five general medical journals. BMJ 2001;323:263-4.

5 Davidoff F, DeAngelis C, Drazen JM, Hoey J, Hojharrd L, Horton R Sponsorship, authorship, and accountability. Lancet 2001;358:854-6.

(Accepted 14 December 2002)

\title{
Total and cause specific mortality among Swedish women with cosmetic breast implants: prospective study
}

\author{
V C M Koot, P H M Peeters, F Granath, D E Grobbee, O Nyren
}

The potential health hazards of breast implants have been heavily debated for the past decade, yet only one study has reported on long term mortality among women with such implants, and around one fifth of the participants were lost to follow up. ${ }^{12}$ We assessed total and cause specific mortality among Swedish women who underwent augmentation mammoplasty between 1965 and 1993. As a desire for cosmetic surgery represents underlying psychopathology in some patients, we hypothesised that deaths due to suicide may be over-represented. ${ }^{3}$

\section{Subjects and methods}

Details about accrual of the cohort have been given elsewhere. ${ }^{4}$ We obtained records from the Swedish Inpatient Register of all 15-69 year old women who had had breast implants $(n=7585)$ in 1965-93. We identified records with erroneous registration numbers or where emigration or death occurred before surgery through linkages with registers held by Statistics Sweden, using the unique national registration numbers. We excluded such records and records where surgery occurred at hospitals without surgical services $(\mathrm{n}=138)$. We also excluded women who had received an implant after surgery for breast cancer ( $\mathrm{n}=3926)$, identified through the cancer register. The final study cohort comprised 3521 women, with a mean age of 31.6 (SD 8.6) years.

Follow up started on the day of first implantation surgery and stopped at date of emigration, death, or end of follow up (31 December 1994), whichever occurred first. The cohort members were followed for an average of 11.3 (range 0.3-29.9) years, corresponding to 39735 person years at risk. We compared the observed number of deaths with the expected number of deaths, the ratio of these two numbers giving the standardised mortality ratio. We obtained the expected number of deaths by multiplying the observed number of person years at risk in the cohort, divided into 5 year age strata and 1 calendar year strata, by the stratum specific mortality rates, derived from official Swedish death statistics. The standardised mortality ratio can therefore be viewed as a measure of relative risk, with the Swedish female population matched for age and calendar year serving as reference. We calculated 95\% confidence intervals, assuming that the number of observed events followed a Poisson distribution. We coded underlying causes of death according to the international classification of diseases ( 7 th, 8 th, and 9th revisions) into suicide, unintentional injury, cardiovascular diseases, malignancies, and other causes.

\section{Results}

Although 58.7 deaths were expected, 85 women died (standardised mortality ratio $1.5,1.2$ to 1.8 ; table). Fifteen women committed suicide, compared with 5.2 expected deaths $(2.9,1.6$ to 4.8$)$. Excess deaths were also due to malignant disease $(1.4,1.0$ to 1.9$)$, mainly lung cancer. The number of deaths for all other causes was close to expected.

\section{Comment}

Women who undergo cosmetic surgery for breast augmentation are more likely to commit suicide than women from the general population. The $50 \%$ excess mortality found by us in our prospective study of 3000 Swedish women contrasts with the decreased mortality reported from the United States. ${ }^{2}$ This may reflect different reasons for self selection for plastic surgery or may be an effect of losses to follow up in the American study. Both the American study and our study did, however, show an increased risk for suicide in women opting for breast augmentation. Our excess

Standardised mortality ratios for total and cause specific mortality in 3521 Swedish women with cosmetic breast implants

\begin{tabular}{lccc} 
Cause of death & $\begin{array}{c}\text { Observed } \\
\text { No of deaths }\end{array}$ & $\begin{array}{c}\text { Expected } \\
\text { No of deaths* }\end{array}$ & $\begin{array}{c}\text { Standardised mortality ratio } \\
\text { (95\% Cl) }\end{array}$ \\
\hline All causes & 85 & 58.7 & $1.5(1.2$ to 1.8$)$ \\
\hline Suicide & 15 & 5.2 & $2.9(1.6$ to 4.8$)$ \\
\hline Unintentional injury & 10 & 5.6 & $1.8(0.9$ to 3.3$)$ \\
\hline Cardiovascular disease & 11 & 11.2 & $1.0(0.5$ to 1.8$)$ \\
\hline Malignancies: & 36 & 25.9 & $1.4(1.0$ to 1.9$)$ \\
\hline Lung & 8 & 2.7 & $3.0(1.3$ to 5.9$)$ \\
\hline Cervix uteri & 3 & 1.2 & $2.5(0.5$ to 7.4$)$ \\
\hline Breast & 4 & 6.7 & $0.6(0.2$ to 1.6$)$ \\
\hline Other causes & 13 & 10.8 & $1.2(0.6$ to 2.1)
\end{tabular}

${ }^{*}$ Based on age specific and calendar year specific death rates in total female Swedish population.
Julius Centre for Health Sciences and Primary Care, University Medical Centre, Box 85500 3508 GA Utrecht,

Netherlands

V C M Koot clinician

P H M Peeters associate professor D E Grobbee professor

Department of Medical

Epidemiology, Karolinska Institute Box 281, S-171 77

Stockholm, Sweden

F Granath associate professor

O Nyren professor

Correspondence to: V C M Kuck-Koot, Comprehensive

Cancer Centre

Middle

Netherlands, PO Box 19079, 3501 DB Utrecht,

Netherlands kuckkoot@ikmn.nl

BMJ 2003;326:527-8 